\title{
The Continuous Existence and Development of Intangible Cultural Heritage Resources of Minority Traditional Sports in Universities
}

\author{
Dongying Li \\ School of Physical Education, Yunnan Minzu university \\ Kunming China
}

\begin{abstract}
Intangible Cultural Heritage Protection brings new opportunities to the development of China's Minority Traditional Sports. Minority Traditional Sports have been attached more and more attention for its unique body movement and appliances. This paper analyzes the importance of Intangible Cultural Heritage Project of Minority Traditional Sports, and incorporates these projects into curriculums in universities. The main conclusions are as following. With its special functions, College can provide a stronger theoretical support for Intangible Cultural Heritage of Traditional Minority Sports and make research more continuous. Make use of the propaganda advantage of colleges and universities, more students are exposed to traditional ethnic sports through physical education curriculum resources. Recommendations reached are as follows. Strengthen the sports disciplines of "Intangible Cultural Heritage of Sports"; enhance teachers' training, and promote teache rs to update teaching philosophy; establish and improve the policy and other expenses guarantees for the development of Intangible Cultural Heritage of national traditional sports curriculum resources.
\end{abstract}

Keywords — Intangible Cultural Heritage, Minority Traditional sports;

\section{INTRODUCTION}

Sport itself is the carrier of culture. Minority Traditional Sports express the national characteristics, consciousness, cultural values and spiritual ideas by its special physical motion and the use of specific sports equipment. Through sports, the national cultural information of a specific area is passed on from generation to generation. On May 20, 2006, the State Council announced the first batch of national "Intangible Cultural Heritage". Wrestling in Yi people, Manchu pearl balls and many other ethnic traditional sports are included. And it is clear that the traditional national sport is intangible cultural heritage. The regional, ethnic, diversity and entertainment of Minority Traditional Sport have played a significant role in the development of sports undertakings in China as well as the promotion of Oriental Sports culture. Universities, as special cultural heritage carriers, have their own special advantages in the protection of intangible cultural heritage in China. By carrying out researches on intangible cultural heritage of sports in universities, Intangible Cultural Heritage of traditional national sport can be better promoted. And thus, more and more people come to know traditional minority sports.

II. Methodology

\section{A Literature:}

Through the analysis of a large number of relevant literatures, characteristics and laws are summarized.

B Interview:

According to the research purpose and mission, experts and successors of sports and intangible cultural heritages are visited or consulted by telephone.

\section{Results and discussion}

\section{A. The Importance of Intangible Cultural Heritage of Minority Traditional Sports Protection}

1) The Significance of Intangible Cultural Heritage of Minority Traditional Sports Protection.

As an important part of the cultural heritage of mankind, intangible cultural heritage of sports has played an important role in the evolution of human civilization. And unlike other types of sports in Intangible Cultural Heritage of Traditional Sports, the origin and development of minority traditional sports are accompanied by festive ceremony of the nation and folk customs, which bear strong regional, entertainment and public participation. It is a part of the cultural heritage of national spirit, and also is the guarantee to ensure our national diversity.

With the rapid economic development, many traditional national sports originate and develop from farming community have been impacted by modern industrial development in the West. Many traditional national sports are gradually fading out of the mainstream of sports culture. And the major manifestations of traditional minority sports such as worship, festivals, etc., have been forgotten in the fast-paced urban life. The development of minority traditional sports is losing its core content, which increases the difficulty of protecting our minority traditional sport. In this context, it is an inevitable requirement to protect national traditional sports in the human civilization. It is also an important part to achieve a universal coordinated development of material civilization and spiritual civilization.

Traditional sports with national characteristics are the base to ensure cultural diversity. And it plays an indelible role in the 
protection of cultural characteristics of various ethnic groups. In some traditional ethnic sports tournament, sports items are the national card, which bears great significance in enhancing national pride and promoting exchanges and understandings between various ethnic groups.

2) Significance of Intangible Cultural Heritage of Minority Traditional Sports in College Sports Education As excellent heritage places of human culture, colleges and universities are responsible for the research and dissemination of human multi-culture. The introduction of intangible cultural heritage of traditional sports to the college sports classrooms can not only rich teaching content of traditional sports, but also enable more students to understand the cultural background of their nation and other nations. While obtaining fitness and entertainment, they can increase their knowled ge, and better understand the connotation of intangible cultural heritage, which will play an irreplaceable role in the inheritance and promotion of national culture in the future.

Many Intangible Cultural Heritages of Traditional National Sport are facing difficulties of reduced number of inheritors and older. Therefore, while establish Intangible Cultural Heritage Protection Research Center in colleges, we also need to actively cultivate culture workers and professional talent related to intangible cultural heritage protection. Thus, our protection work can be carried out in an orderly manner, and with successors. Meanwhile, it puts forward higher requirements on the university PE teachers. The majority of teachers need to continuously enrich their historical and cultural knowledge of intangible cultural heritage, use different ways and means to disseminate these in the classroom, enrich teaching methods, as well as deepen teaching reform.

Chinese National Traditional Sports carry values of the Chinese nation. By incorporating intangible cultural heritage resources of traditional sports into the physical education curriculum in universities, students can participate in the projects and understand the characteristics of these projects. Teachers guide students to understand the cultural background, and enhance students' sense of national pride and inspire students' patriotism.

\section{B. The Development and Utilization of Intangible Cultural Heritage Resources of Minority Traditional Sports in Universities PE courses}

According to the requirements of combining National Traditional Sports with School Physical education, the traditional national sports are divided into the following types: playful entertainment, rodeo class, festive custom class, etc. Colleges and universities, when using these resources, should take into account the characteristics of the student's age. While meet students' needs of fitness and recreation, the feasibility, practicality and generalization of the projects ought to be considered as well.

\section{1) Objectives and Principles of the Curriculum Development and Utilization of Intangible Cultural Heritage Resources of Minority Traditional Sports}

In the process of curriculum development of Intangible Cultural Heritage Resources of Traditional sports, we have to put the principle of meeting students' fitness needs at the first place. The course should provide students with a wealth of intangible cultural heritage resources, cultivate their exercise consciousness of "lifetime sports", and promote their comprehensive development.

China's traditional culture is colorful, and many outstanding heritages cannot be covered by a single category. For example, $\mathrm{Xu}$ water lion in Hebei is normalized to a folk dance project. But in the sports field, it also has been classified as a sports project and managed by the Chinese Dragon and Lion Dance Association. Thus, in the development process of intangible cultural heritage resources of traditional national sport, we should be aware of this issue. We cannot find a single type of sports project for that many skills and dance heritage projects can also be used for physical education curriculum. We ought to constantly enrich physical education curriculum system to ensure the diversity of curriculum resources.

There are many minorities in Yunnan Province. The heritage resources there are rich and the course contents of each region are quite different. So in the process of developing programs, colleges throughout the county should form a unique traditional sports course based on the specific location of the school, school conditions and students.

Some intangible cultural heritages of sports make use of sports equipment, such as tuoluo, blow guns, etc. hence, in the process of curriculum development, safety issues need to be put at the first place. The development of curriculum should be in accordance with the specific conditions of the school, actual situation of students and so on.

\section{2) Resource Development of Intangible Cultural Heritage of Minority Traditional Sports in College Sports}

\section{Courses}

a) Hardware Curriculum Resources.:Teaching material. China's traditional sports culture has a long history, and there are a wide variety of projects. When the school is required to develop curriculum resources, appropriate intangible cultural heritage materials of sports, which act as a guide for PE teachers, are needed. Consequently, universities ought to organize professional personnel or teachers to mine and collect materials. Sort out the history, evolution and culture connotation of these projects into a book. A good textbook can fully stimulate students' interest, and cultivate students' exercise consciousness.

b) Stadiums. Many intangible cultural heritage items of traditional national sports are derived from people's production, labor work, and other sacrifice festivals. There is no fixed standard requirement on the stadium. Then in the process of carrying out projects in university, we can take advantage of the existing track and field and basketball court resources in school. If the school's sports resources can not meet the needs, we can also develop and make use of the surrounding community sports stadium. Even we can find suitable sports venues in the nature.

c) Minority Traditional Sports Gallery. At this stage, most materials and appliances of Intangible Cultural Heritage Items of National Traditional Sports are displayed in the local museum. Projects are scattered in the 
birthplace of the respective sports. Then, colleges can handle those materials and information about the successors collectively. Colleges and universities are effective ways to promote, protect and inherit these intangible cultural heritage items.

d) Electronic equipment. With today's high-tech development, we can take advantage of multi-media class-rooms, slides, network for teaching. With the help of three-dimensional animation we can demonstrate some uncommon traditional sports. We are also able to record teaching films about Intangible Cultural Heritage of Traditional National Sports to carry out a more comprehensive promotion. Thus, enable more people to understand and master the techniques of these sports.

e) Software Courses Resources: Sports Talent. Many inheritance of Intangible Cultural Heritage of National Traditional Sports rely on oral presentation and hands-on demonstrations. At this stage, a lot of national traditional sports are faced with the problem of successors are old while the younger generation is not interested in the project, causing a situation of no successor. With personnel training and promotion of the project in universities, we can increase young people's understanding of the project and motivate their learning. Focus on training students who obtain a good foundation, improve their skills to master the project, deepen their understanding of cultural background, enhance their theoretical and skill level so as to be a qualified successor. Minority areas, which have reserved personnel trainings, can use modes of professional minority traditional sports single entrance examination or examinations to recruit high-level athletes to enroll these athletes into college physical education. Provide these athletes with a more systematic study of sports science knowledge, and make use of the convenience in colleges to promote minority traditional sports.

The carrying out of Intangible cultural Heritage of Traditional Sports is inseparable from professional teachers. We need professional training for teachers so that teachers can have a comprehensive, in-depth knowledge of the system of Intangible Cultural Heritage of National Traditional Sports. Thus they are capable of the work from theory to practice. Encourage teachers to do research and carry out research activities related to Intangible Cultural Heritage of Traditional Ethnic Sports. Also, teachers ought to improve the culture of self-cultivation continuously, study the Intangible Cultural Heritage of National Traditional Sports deeply. At the same time, colleges and universities can also employ a number of projects heirs to teach and communicate, and then facilitate the promotion and development of these projects

f) Information Resources of Intangible Cultural Heritage of Traditional Ethnic Sports. Materials can be collected by a variety of ways, such as the local library, the Internet, television, sports magazines, etc. Upload the sorted conversation with the heirs of project as well as the learning content. Let more people understand these intangible cultural heritage items of national traditional sports.

g) Sports curriculum resources. Although some minority traditional sports have not been included in the Intangible Cultural Heritages list, these projects bear good promotion potential. Therefore, they can also be one of the teaching contents in the curriculum so as to enable the majority of teachers and students to get more sports knowledge, skills and information.

\section{Factors Constrain the Development and Utilization of Intangible Cultural Heritage Resources of MinorityTraditional Sports in College Sports Curriculum}

\section{1) Imperfect Development of Curriculum Resources}

China is rich in Intangible Cultural Heritage resources of Traditional National Sport. Development and utilization of Intangible Cultural Heritage resources of Traditional National Sport vary according to different regions, different cultural backgrounds and different levels of teachers and students. Only by constant practice of digging and practicing can we find out the appropriate course resources in college, for example, the use of resources in the venues and facilities. In some colleges, the playgrounds are closed during the after class time. What's more, sports equipment shall not be lent out and other factors impede development and utilization of curriculum resources of Intangible Cultural Heritage of Traditional Ethnic Sports.

2) Shortage of Teachers

Teachers are in a very critical position in the process of developing and utilizing course. The spread of these projects requires teachers to play the role of learning and teaching. However, the number of teachers in China specializing in national traditional sports teaching is less and can not meet the needs of intangible cultural heritage of national traditional sports courses. Therefore, in the process of development, some PE teachers need to accept re-training and training. There will inevitably be some imperfections in the process of studying and teaching, hence, we should constantly strive to innovate and improve our knowledge.

3) Attention and Support from Leaders in Colleges

Whether an educational reform is successful or not, the attention and support from leaders is a prerequisite. Some leaders ignore the construction of college sports, and are indifferent to school sports. All these will indirectly affect enthusiasm and creativity of teachers. At the same time, construction of sports facilities also needs the support from leaders. Many intangible cultural heritage projects of traditional national sports require special sports equipment. Then, it will be affected by the use of funds.

4) Educational Evaluation System

In the process of selecting and formulating curriculum resource, it is important to establish a reasonable evaluation system. For some intangible cultural heritage items, difficulty may exist in establishing the evaluation system, which is not conducive to the development of the project in university sports curriculum. Only by fully playing the guiding role of educational evaluation, motivate students and teachers to creatively develop and utilize heritage resources, can we dig out 
sports curriculum that is good for students' body and mental health, and stimulates their interest and enthusiasm. 4. Conclusions and Recommendations.

\section{CONCLUSIONS AND RECOMMENDATIONS}

\section{A. Conclusions}

1) With special functions, colleges provide a strong theoretical research support for Intangible Cultural Heritage of Minority Traditional Sports, making research more continuous.

2) We can make use of the advantages of college propaganda. More students are exposed to traditional ethnic sports through physical education curriculum resources. Thus, further enhance the students' awareness of traditional ethnic sports culture and increase national pride.

3) At this stage, due to space limitations and other conditions, development of some Intangible Cultural Heritage of Minority Traditional Sports will be subject to certain obstacles.

\section{B. Countermeasures and Suggestions}

1) Strengthen the Construction of Sports Disciplines --- "Intangible Cultural Heritage of Sports”

For Intangible Cultural Heritage of Sports, there is still no independent disciplinary system, which is not conducive to the construction of Intangible Cultural Heritage of sports and promotion of physical education curriculum in colleges and universities. It is a feasible way to incorporate intangible cultural heritage of sports into traditional national sport disciplines. It can not only enrich the content of traditional national sport disciplines, but also promote the protection and construction of intangible cultural heritage of sports.

2) Strengthen Teachers' Training and Encourage Teachers to Update Teaching Philosophy

In the process of sports curriculum development, teachers play a key role. Teachers are both subject of curriculum development as well as a part of preaching in the process of teaching. Therefore, their quality determines the development and utilization degree of curriculum resources. Teachers should constantly update their knowledge, acquire more knowledge and skills about intangible cultural heritage of sports by participating training. Also, they can carry out scientific research after learning systematically to deepen their understanding of the curriculum. Thus, more curriculum resources suit local school characteristics will be developed in the process of continuous learning.

3) Establish and Improve Policy and Funding Guarantees for the Development of Intangible Cultural Heritage of National Traditional Sports Curriculum Resources

For the emerging intangible cultural heritage of national traditional sports programs, policies and funding need to be guaranteed. Equipment, facilities and other venues should be available to teachers and students, which lay a solid foundation for physical education teachers to research and develop intangible cultural heritage resources of national traditional sports.

\section{REFERENCES}

[1] Yuping Shao, Protection and Inheritance of Non-materialistic Cultural Heritage of the National Traditional Sports [J], Journal of Guangxi Normal University (Philosophy and Social Science Edition), 2011(12): 115-118

[2] Haoliang Sun, Jing Wang, On Preservation of Intangible Culture Heritage of National Traditional Sports [J], Journal of Guizhou Normal University (Social Science), 2009 (5): 58-62

[3] Ying Peng, Jianqiang Feng, Baolu Zou, Jianzhe Zhang, Practice of Introducing "Intangible” Resources to Hebei Physical Education in Higher Institutions[J], Journal of Hebei Institute of Physical Education, 2011(7):48-51

[4] Jianwei Jia, Development and Utilization of Traditional Ethnic Sports Curriculum Resources in Southeast- ern Regions of Chongqing from the Perspective of Intangible Cultural Heritage Protection [M], Southwest University, 2010

[5] Hongjie Sun, Roles of Universities in Xinjiang Played in the Protection of Intangible Cultural Heritage[M], Shihezi University, 2008 